\title{
A NOVEL PROXIMITY COUPLED ACTIVE INTEGRATED ANTENNA
}

\author{
Sasidhar Vajha*, Member, IEEE, and Prasad Shastry**, Senior Member, IEEE \\ *MMIC Design Engineer, TLC Precision Wafer Tech Inc, 1411, W. River Road N., Minneapolis, MN 55411, USA \\ Tel: +1(612)341-2795, Fax: +1(612)341-2799, Email: svajha@tlcprecision.com \\ **Professor, Dept. of Electrical and Computer Engg., Bradley University, 1501, W. Bradley Ave., Peoria, IL 61625,USA \\ Tel: +1(309)677-2733, Fax: +1(309)677-3670, Email: snp@cegt201.bradley.edu
}

\begin{abstract}
In this paper, a novel design approach and measured results of a compact proximity coupled active integrated antenna (PCAIA) are presented. A new type of antenna feed structure is proposed. A single self-biased (through the RF port), two-stage low noise amplifier has been integrated with a proximity coupled patch antenna having a new feed structure. The proposed approach is useful in the design of compact PCAIA with good radiation characteristics for applications in microwave wireless systems.
\end{abstract}

\section{INTRODUCTION}

The advantages of Active Integrated Antennas (AIAs) for applications in microwave and millimeterwave integrated transceivers in wireless systems is well known [1-3].

However, integration of the active circuitry and the microstrip patch antenna using the basic feeding techniques on a single substrate will not achieve compact circuit size and good radiation characteristics simultaneously. The patch antenna requires a low $\epsilon_{\mathrm{r}}$, thick substrate for good radiation characteristics [4-10], whereas the RF circuitry requires a thin, high $\in_{\mathrm{r}}$ substrate for size reduction and low radiation loss.

Proximity coupled (PC) patch antennas, due to their multilayer architecture, provide a solution for developing a thin and compact feed network without compromising the antenna performance. This type of patch antennas is reported to have achieved higher bandwidths compared to other feeding techniques [6-8]. However, no reports have demonstrated a PC patch antenna with the feedline on very high $\in_{\mathrm{r}}(>5)$ and thin $(\mathrm{h}<50 \mathrm{mil})$ boards due to the inadequate coupling between the conventional $50 \Omega$ feedline and the patch antenna on these boards. A modified feedline approach on a high $\epsilon_{\mathrm{r}}$ and thin board for use in the PC patch antenna configuration is necessary.

In the AIA presented here, a PC patch antenna is integrated with a two-stage GaAs FET LNA. A new type of feedline has been developed to achieve better radiation characteristics for the patch antenna, using a very high dielectric constant $\left(\epsilon_{\mathrm{r}}=9.2\right)$ and thin $(\mathrm{h}=30 \mathrm{mil})$ substrate for the feedline and LNA. The active antenna is biased through the RF port.

The PCAIA design approach and measured results are presented in the following sections.

\section{PC PATCH ANTENNA DESIGN}

The geometry of the new proximity coupled active integrated antenna with a widened feedline is shown in Fig. 1. The widened feedline increases the capacitive coupling between the patch radiator and the feedline, hence improving the radiation characteristics of the antenna. The substrates were chosen to simultaneously achieve minimum LNA circuit size and good antenna radiation characteristics.

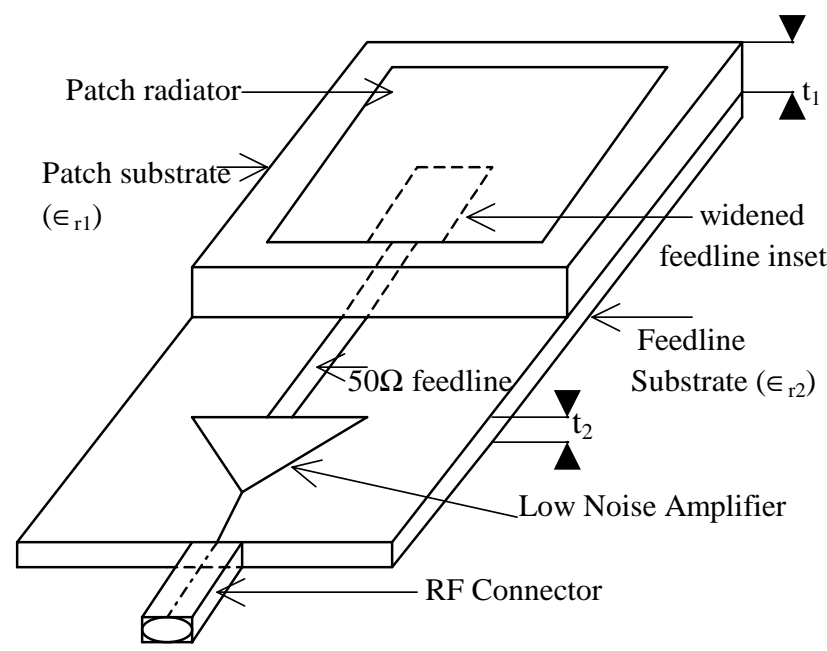

Fig. 1. Geometry of the proposed proximity coupled Active Integrated Antenna (PCAIA) with widened feed line inset

A 30 mil thick $\left(\mathrm{t}_{1}\right)$ substrate with a high dielectric constant (TMM10i from Rogers Corp.; $\in_{\mathrm{r}}=9.8$ ) was selected for the feedline and the active circuit. A 120 mil thick $\left(\mathrm{t}_{2}\right)$ substrate with a low dielectric constant (RT duroid 5870; $\epsilon_{\mathrm{r}}=2.33$ ) was selected for the patch radiator. The design guidelines suggested in [9], and [10] were followed in the design of the PC patch antenna for a resonant frequency of $1.9 \mathrm{GHz}$. Patch length was calculated to be $4.7988 \mathrm{~cm}$.

Various widened feedlines of characteristic impedances $50 \Omega, 40 \Omega, 30 \Omega, 20 \Omega, 10 \Omega, 8 \Omega$, and $5 \Omega$ were fabricated 
TABLE I

MeAsured Results Of The PC Patch ANTENNA With WIDENED FEEDLINE INSETS (50\% overlap with patch)

\begin{tabular}{|c|c|c|c|c|c|c|c|}
\hline $\begin{array}{l}\text { Characteristic } \\
\text { impedance of } \\
\text { the feedline } \\
\text { inset }(\Omega)\end{array}$ & 50 & 40 & 30 & 20 & 10 & 8 & 5 \\
\hline $\begin{array}{l}\text { Width of the } \\
\text { feedline inset } \\
\text { (mil) }\end{array}$ & 29.3 & 44.6 & 71.6 & 128 & 300 & 389 & 655 \\
\hline $\begin{array}{l}\text { Resonant } \\
\text { frequency of } \\
\text { the PC patch } \\
(\mathrm{GHz})\end{array}$ & 1.8 & 1.8 & 1.8 & 1.84 & 1.84 & $\begin{array}{c}1.84 \\
\text { and } \\
1.5\end{array}$ & 1.48 \\
\hline $\begin{array}{l}\text { Return loss of } \\
\text { the PC patch } \\
\text { (dB) }\end{array}$ & -2.0 & -2.3 & -3.9 & -6.8 & -3.4 & -3.0 & -3.5 \\
\hline $\begin{array}{l}\text { Input } \\
\text { impedance of } \\
\text { the PC patch } \\
(\Omega)\end{array}$ & $\begin{array}{c}6+ \\
j 12\end{array}$ & $\begin{array}{l}8+ \\
\text { j1 }\end{array}$ & $\begin{array}{l}17+ \\
\text { j32 }\end{array}$ & $\begin{array}{l}38+ \\
\text { j58 }\end{array}$ & $\begin{array}{c}217 \\
+\mathrm{j} 95\end{array}$ & $\begin{array}{c}282 \\
-\mathrm{j} 53\end{array}$ & $\begin{array}{c}12 \\
-\mathrm{j} 11\end{array}$ \\
\hline $\begin{array}{l}\text { Input } \\
\text { Impedance } \\
\text { point in Fig. } 2\end{array}$ & A & B & C & D & E & $\mathrm{F}$ & $\mathrm{G}$ \\
\hline
\end{tabular}

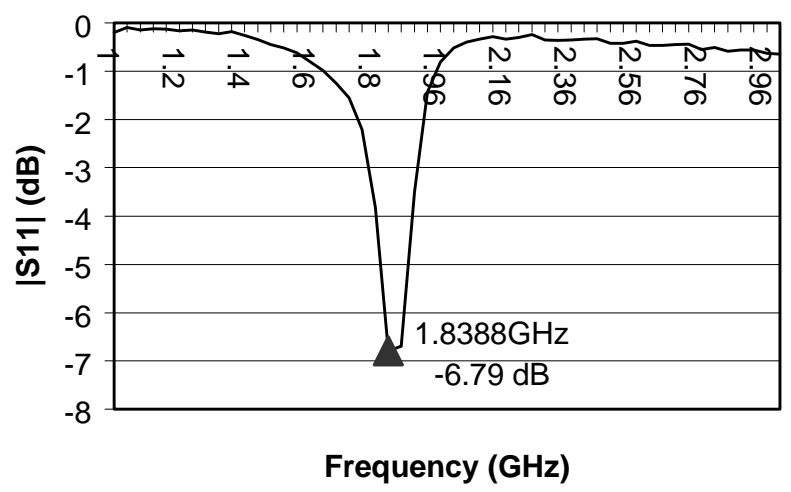

Fig. 3. Measured return loss of the PC patch antenna with a $20 \Omega$ feedline inset

to test the antenna performance. A feedline overlap of 50\% with the patch antenna was considered. Table I summarizes the measured results for various widened feed line insets. Minimum return loss occurred for the feedline having $20 \Omega$ characteristic impedance. The results also show that further widening of the feedline would make the effective feedline-antenna combination to resonate at a different frequency.

Input impedances of the antenna with various feedlines at the resonant frequencies are shown on the smith chart in Fig.2. Points A, B, C, D, E, F, and G in Fig.2 correspond to the input impedances of the PC patch antenna with widened feedline insets of characteristic impedances $50 \Omega$, $40 \Omega, 30 \Omega, 20 \Omega, 10 \Omega, 8 \Omega$, and $5 \Omega$, respectively. It can be

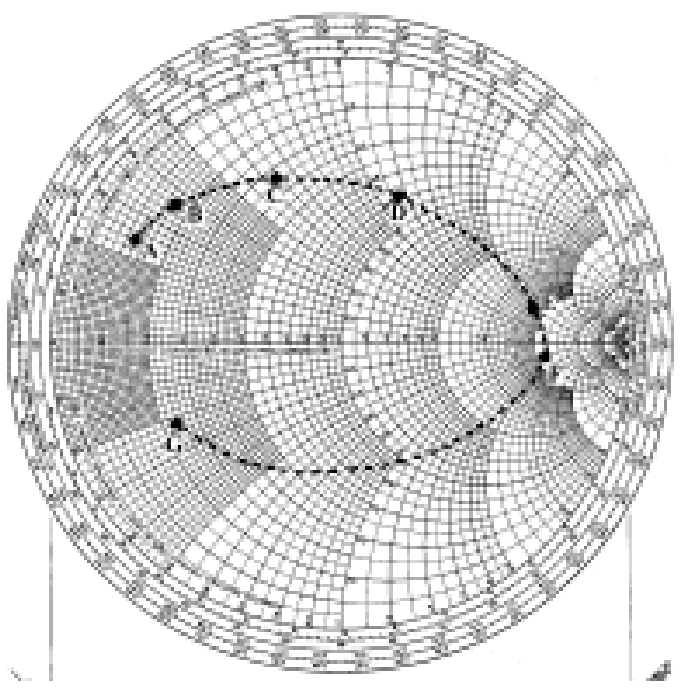

Fig. 2. Measured input impdances of the proximity coupled patch antenna with widened feed lines

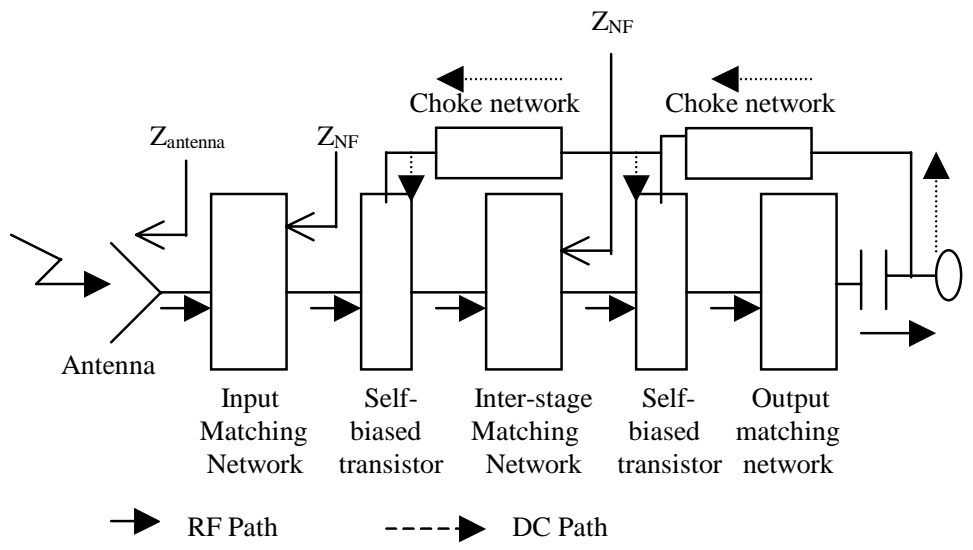

Fig. 4. AIA Architecture

observed that the path traced by the points A-G in Fig.2 follows a regular pattern. This observed phenomena could be further investigated to predict the optimum width of the feedline ( $20 \Omega$ feedline here) required to achieve the lowest return loss for a given PC patch antenna configuration. Also, the input impedance data is useful in the design of a matching network to further reduce the return loss and increase the bandwidth of the antenna as reported in [6].

The optimum feedline with $20 \Omega$ charactersitic impedance was chosen for integration. The measured return loss of this patch antenna is shown in Fig. 3. The input impedance of the antenna is $37.592+\mathrm{j} 57.66 \Omega$ at the resonant frequency $(1.8388 \mathrm{GHz})$. This impedance was used as the source impedance in the design of the LNA. 


\section{AIA LOW-NOISE AMPLIFIER DESIGN}

\section{A. AIA Architecture}

The block diagram of the AIA consisting of an antenna and two-stage LNA is shown in Fig. 4. Unlike the conventional design approach where the antenna and the amplifier are first matched to $50 \Omega$ and then connected together, here the input impedance of the antenna is directly transformed to the source impedance needed for minimum noise figure.

The DC and RF paths in the AIA are shown in Fig.4. The transistors are self-biased from a single DC source, through the RF port.

\section{B. Bias Network and FET stabilization}

Fig. 5 shows the self-biased FET configuration. The transistor used is NE34018, as it has good noise performance and gain in the $\mathrm{L}$ to $\mathrm{S}$ band.

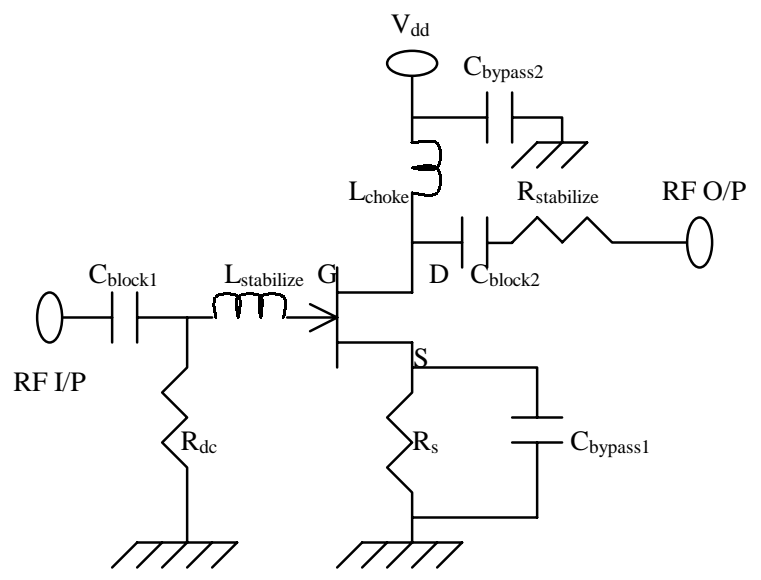

Fig. 5. Biasing, stabilization scheme for the self-biased FET

A bias condition of $\mathrm{V}_{\mathrm{ds}}=3 \mathrm{~V}$ and $\mathrm{I}_{\mathrm{ds}}=20 \mathrm{~mA}$ was selected corresponding to a minimum noise figure of $0.62 \mathrm{~dB}$ $\left(\Gamma_{\mathrm{opt}}=0.62 \angle 42^{\circ}\right)$ and an associated gain of $16.8 \mathrm{~dB}$ at $2 \mathrm{GHz}$.

A $100 \mathrm{~K} \Omega\left(\mathrm{R}_{\mathrm{dc}}\right)$ resistor was chosen to provide a DC ground for the gate. A choke network consisting of a $22 \mathrm{nH}$ inductor $\left(\mathrm{L}_{\text {choke }}\right)$ and a $2400 \mathrm{pF}\left(\mathrm{C}_{\text {bypass } 2}\right)$ bypass capacitor was used to bias the drain. The self-biased transistor was simulated on HPADS considering parasitics associated with the inductors, via posts, and component pads. Simulation results showed that the transistor was unstable. Hence, the transistor was made unconditionally stable with a series inductor $\left(\mathrm{L}_{\text {stabilize }}=10 \mathrm{nH}\right)$ on the gate and a series resistor $\left(\mathrm{R}_{\text {stabilize }}=22 \Omega\right)$ on the drain as shown in Fig.5.

The values of circuit elements needed for stabilization were calculated following the stabilization rules suggested in [11]. The stabilized self-biased transistor was simulated for S-parameters and noise parameters using HPADS circuit simulator. The parameters of the stabilized selfbiased transistor were used in the design of the LNA.

\section{LNA Design}

The low noise amplifier was designed by implementing the matching networks as shown in Fig. 4. Short circuited single stub matching networks were used. The input matching network was designed such that the input impedance of the antenna was transformed to $\mathrm{Z}_{\mathrm{NF}}$, which corresponds to the $\Gamma_{\mathrm{opt}}$ of the self-biased transistor. The inter-stage matching network was designed to transform the output impedance of the first stage to $\mathrm{Z}_{\mathrm{NF}}$ to provide a noise match for the second stage. The output matching network transforms the output impedance of the second

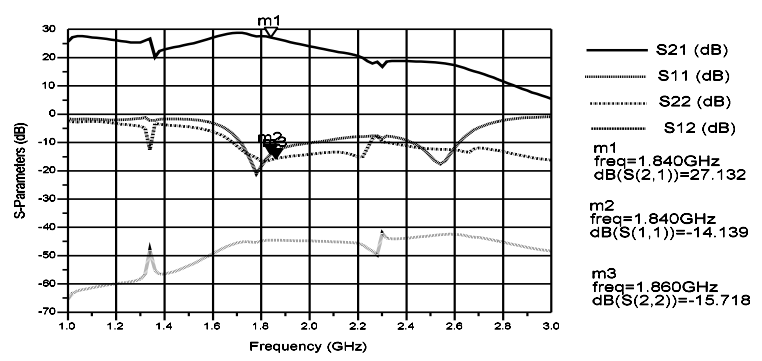

Fig. 6. Simulated S-parameters of the AIA amplifier with input port impedance (source impedance) of $37.592+\mathrm{j} 57.7 \Omega$

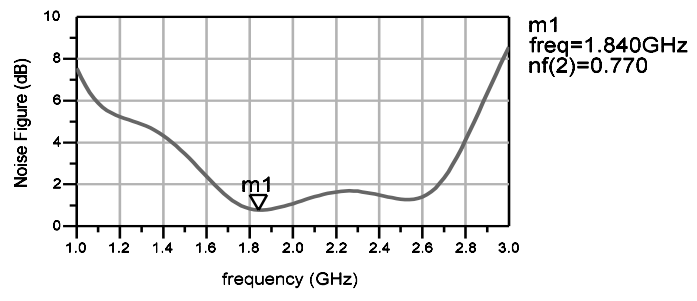

Fig. 7. Simulated noise figure of the AIA amplifier with and input port impedance (source impedance) of $37.592+\mathrm{j} 57.7 \Omega$

stage to $50 \Omega$ port impedance. Choke networks as shown in Fig. 4 were provided to bias the FETs. The $50 \Omega$ input line of the amplifier was extended and widened $(20 \Omega)$ to serve as the feedline for the PCAIA as shown in Fig.1. The amplifier circuit was simulated using HPADS for $\mathrm{S}$ parameters and noise figure. The input port impedance (source impedance) was adjusted to be equal to the antenna input impedance $(37.592+\mathrm{j} 57.66 \Omega)$. The 
simulated S-parameters and noise figure are shown in Fig.6 and Fig.7 respectively. It is evident from Fig.6 and Fig.7 that the LNA has a gain of $27.3 \mathrm{~dB}$, noise figure of $0.77 \mathrm{~dB}$, input return loss of $-14.14 \mathrm{~dB}$, and output return loss of $-15.8 \mathrm{~dB}$ at the design frequency $(1.8388 \mathrm{GHz})$.

\section{MEASURED RESULTS}

The PC patch radiator was fabricated on RT duroid 5870 and the AIA low noise amplifier was fabricated on TMM10i boards, both from Rogers corporation. The radiator and the amplifier were properly aligned and attached. The AIA was mounted in a metal housing. The photograph of the PCAIA is as shown in Fig.8. The PCAIA was tested for gain in the anechoic chamber at Bradley University. The measured gain of the PCAIA was found to be $20 \mathrm{dBi}$. The measured radiation characteristics of the proximity coupled (PC) patch antenna are summarized in Table II.

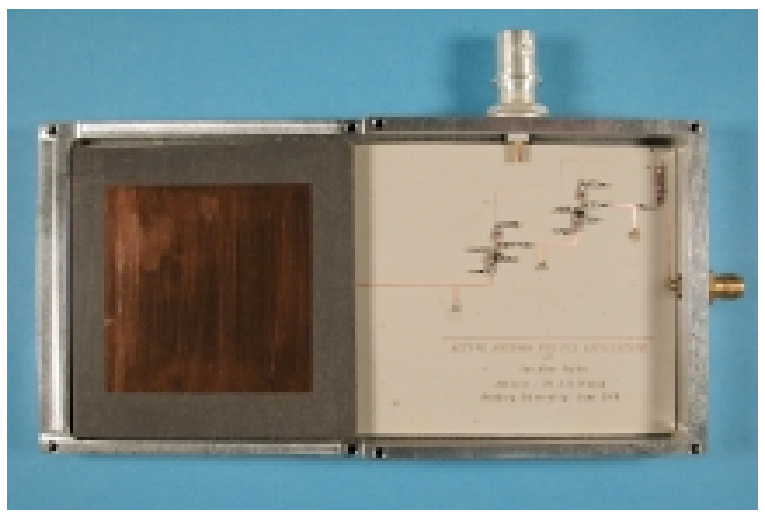

Fig. 8. Proximity coupled Active Integrated Antenna (BNC Connector on top was not used)

TABLE II

MEASURED RADIATION CHARACTERISTICS OF THE PC ANTENNA WITH FEEDLINE INSET OF $20 \Omega$

\begin{tabular}{|l|c|c|}
\hline Characteristic & E-plane & H-plane \\
\hline Beam Width & $75^{\circ}$ & $90^{\circ}$ \\
\hline Side-lobe level & $-14 \mathrm{~dB}$ & $-16 \mathrm{~dB}$ \\
\hline PC Antenna gain & \multicolumn{2}{|c|}{$4 \mathrm{dBi}$} \\
\hline PCAIA gain & \multicolumn{2}{|c|}{$20 \mathrm{dBi}$} \\
\hline
\end{tabular}

\section{CONCLUSIONS}

A novel design approach and measured results for a proximity coupled active integrated antenna (PCAIA) have been presented. A new widened feed structure (on high $\epsilon_{\mathrm{r}}$ substrate) is proposed. The PCAIA inherits well known advantages of the proximity coupled patch antenna. The proposed approach is useful in the design of compact PCAIA having good radiation characteristics for applications in microwave wireless systems.

\section{ACKNOWLEDGEMENT}

The authors would like to thank Mr. David Miller, technician, College of Engineering and Technology, Bradley University, for his help in this project.

\section{REFERENCES}

[1] Yongxi Qian and T.Itoh, "Progress in Active Integrated Antennas and Their Applications," IEEE Transactions on Microwave Theory and Techniques, Vol. 46, No. 11, pp.1891-1900, November 1998.

[2] M.J. Cryan and P.S. Hall, "An Integrated Active Circulator Antenna," IEEE Microwave and guided wave letters, Vol.7, No. 7, pp. 190-191, July 1997.

[3] A.S. Andrenko and et.al, "Impedance Matching in Active Integrated Antenna Receiver Front-end Design," IEEE Microwave and Guided Wave Letters, Vol. 10, No. 1, January 2000, pp. 16-18.

[4] C.A. Balanis, "Antenna Theory, Analysis and Design," John Wiley \& Sons Inc., 1997.

[5] Dr. Max Amman, "Design of Rectangular Microstrip Patch Antennas for the $2.4 \mathrm{GHz}$ Band," Applied Microwave \& Wireless, pp. 24-34, Nov./Dec. 1997.

[6] D.M. Pozar and B. Kauffman, "Increasing Bandwidth of a Microstrip Antenna by Proximity Coupling," Electronics Letters, Vol.23, No. 8, pp. 368-369, April 1987.

[7] G. Splitt and M. Davidovitz, "Guidelines for Design of Electromagnetically Coupled Microstrip Patch antennas on Two-layer substrates," IEEE Transactions on Antennas and Propagation, Vol. 38, No. 7, pp. 1136-1140, July 1990.

[8] Daniel H. Schaubert, "A Review of Some Microstrip Antenna Characterstics," Microstrip Antennas, IEEE Press, pp. 59-67, 1995.

[9] Sasidhar Vajha, "A Proximity Coupled Active Integrated Antenna," MSEE Project Report, Bradley University, Peoria, Illinois, 2000.

[10] Sasidhar Vajha and S.N. Prasad, "Design and Modeling of Proximity Coupled Patch antenna," 2000 IEEE AP-S Conference on Antennas and Propagation for Wireless Communication Digest, pp. 43-46.

[11] G. Gonzalez, "Microwave Transistor Amplifier Design," Prentice Hall, 1998. 